\title{
A comprehensive organisational model for the effective management of project management
}

\author{
C.J. Brown* \\ University of Stellenbosch Business School, University of Stellenbosch, \\ PO Box 610, Bellville 7535, Republic of South Africa \\ cjb2@usb.ac.za
}

Received June 2008

\begin{abstract}
This paper is not primarily aimed at project leaders, but at the decision-makers on project management in organisations. The purpose is to expose the not-so-obvious organisational complications which confront project managers in the management of projects. The point of departure is to establish a comprehensive approach to creating an organisational environment conducive to project management excellence in an organisation.
\end{abstract}

In the arenas of business and management, the principles of project management is relatively simple and much of it actually common sense. However, it is the experience of many project leaders that the mere application of appropriate project management processes and techniques, by no means guarantee that the management of projects will be effective on a continuous basis. On investigation of that premise, this paper reports on research that identified organisational variables that can affect the organisational strategy, structure, culture, systems, behavioural patterns and processes of an organisation, which comprehensively determine the internal environment pre-requisites for project management to be exercised successfully.

The rationale of the paper is to re-emphasise, but also to investigate progress on the stern warning by Nicholas (1990: 481) nearly two decades ago that organisations should not jump into project management precipitously, but with a welldeveloped and organisation-fitted strategy and game plan.

*To whom all correspondence should be addressed.

\section{Introduction}

For the purposes of this paper it is considered common knowledge that project management concerns the achievement of ad-hoc, complex goals (Kerzner, 1992:1-6; Gray \& Larson, 2008:5,6). The successful management of a project depends heavily on the systemic integration and scheduling of multifunctional inputs into a single point of responsibility, authority and leadership (Cleland, 1990:1 18; Mantel, Meredith, Shafer \& Sutton: 2001, 38 - 52). Numerous informal interactions by the author with experienced practitioners, revealed their wide spread concern that a common perception persist amongst high level managers that practicing project management in an organisation is a simple matter of defining a project goal, putting a team of functional experts together, appointing the project leader and applying the project management principles and techniques. However, as stated by Nicholas (1990:481) nearly two decades ago, introducing and establishing project management in formerly functionallyonly structured organisations is mostly a complex process with several implications for the organisation, which require much more involvement of the high level management than they apparently, commonly anticipate. Since the statement by Nicholas in 1990, much research had been done on some of the variables that determine those implications, including the author and associates' research. No evidence of an approach to address comprehensively all the variables, as indicated in this paper could, however, be found.

Therefore this paper reports on and collates the results of several literature, empirical and experiential studies by the author and others, which identified seven organisational dimensions, that collectively so significantly influence the practice and ultimately the success of the management of projects, as to be deemed imperative for the effective management of project management. These dimensions pervade the organisational strategy, structure, culture, systems, behavioural patterns and processes of an organisation, thereby determining the internal environment required for project management to be exercised successfully. These seven dimensions are expounded in this paper as seven consecutive steps towards building a comprehensive organisational model for the effective management of project management in an organisation..

\section{First dimension: Formalise the organisation's approach to project management}

One of the most widely reported results of research on the practicing of project management in formerly functionallyonly structured organisations, is that an informal approach to project management is a sure path to disaster (inter alia Nicholas, 1990:481; Kezsbom \& Edward, 2001:27 - 40; 
Mantel et al., 2001:35; Frigenti \& Comninos, 2002:45 \& 332). Mantel et al., 2001:35 are even of the opinion that the more complex an organisation's projects are, the more formal the approach or style of project management should be.

Formalising project management requires that an organisation-wide strategy for project management must be initiated and visibly supported by top management. Tettemer (1991), Brown (2000) and Botha (2003) assert that a strategy is essential, because it is a prerequisite for the displacement of traditional relationships and practices with new ones. It also serves to comfort high level administrators during the period of change. It will also demonstrate top management's belief in the validity of the project management process. Because project leaders have in principle only one chance (a project is executed only once with no or very little rehearsal), their decisions must be right the first time. There should therefore be consistency about the cause-and effect-relationships of their decisions, which only a well-structured strategy and the resulting policies can provide.

During a well monitored case study in a South African local authority over a period of three years, (Brown \& Botha, 2005:1 - 7), a strategy containing twelve (generic) elements for the implementation of project management in a formerly functionally-only structured organisation was developed and tested. The basic approach was to establish a project office with the project leaders acting in a weak to balanced matrix relationship with the various, strictly functionally organised departments. This strategy evolved from previous literature studies by Botha (2003), practical experience of three limited efforts to implement project management in other various organisations by Brown (1997), as well as an experiential learning approach with the implementation process. These elements are summarised as follows:

1. Firm commitment from top management is the first step. Unequivocal and visible support for a transition to the project management way of goal achievement and the appurtenant actions must be communicated to the entire organisation by way of a clear and unambiguous declaration of strategic intent.

2. A Project Management Steering Group (PSG) must be established to oversee the development and implementation of the strategy (Kezsbom \& Edward, 2001:28 \& 31). It should report directly to the CEO's office, representing all the affected functional departments, and the members of the project office setting out on their new careers. The task of the PSG is to assure adherence to sound principles, to mediate in all conflict situations and to eventually develop a customised project management methodology for the organisation. In the case study mentioned this group kept up the interest and constantly marketed project management when considerable conflict and turmoil (apparently typical of most local authorities in South Africa) swept the organisation.

3. Implementing project management should be organised and managed as a project in own right. A major advantage thereof, is the implication that a project plan will have to be drawn up BEFORE the actual steps are put in action, as per Clements \& Gido (2006:78), "first plan the work, then work the plan”. I.e. the expected deliverables, tasks, workflow and allocation of resources are to be articulated on paper BEFORE action is taken. Presenting the plan to all the stakeholders results in common understanding of what lies ahead for the organisation. A well developed project plan also leads to benchmarking of progress against predetermined measurable norms, clearly established responsibilities, authorities and accountabilities. By inference a project leader to take responsibility for this project, needs to be appointed.

4. The implementation project should be mentored by an established and independent project management professional. In the case study it quickly became very clear that functionally structured organisations do not have staff sufficiently skilled to confidently act as project leader for the implementation project. On the other hand, from a viewpoint of enhancing buy-in, an outsider as the project leader was not successful; therefore the guidance of a mentor to a "local" project leader was indispensable, as an expert advisor on best practises, as an external evaluator of the project's progress and to facilitate progress assessment meetings from an unprejudiced point of view.

5. Resistance to change is the omnipresent phenomenon in transformational management. Knutson (1994:437) warns that project management represents a major departure from the traditional business processes of functionally orientated organisations. Therefore a change management program, as a concurrent, subproject aimed at the directors/councillors, top management officials and customers alike must be included in the project plan. This process has to be managed meticulously because management must be able to distinguish between resistance to change as a result of the project management implementation, or as a result of other internal or political matters impacting on organisational behaviour.

6. In many organisations non-functional management is not provided for, i.e. the management of activities or decision making outside the jurisdiction of a linefunction is not facilitated or even permitted. However the project leader, by definition, has primary control over the resources and the project's direction (Ford \& Randolph, 1992:271). Also, career models for project leaders do not exist in functionally structured organisations. Therefore, for the sake of good governance, adaptations to the de facto organisation structure to provide for a complete design of the authorities, performance criteria, career paths and remuneration structures for project leaders must receive high priority. 
7. Restructuring of the Financial Management system is the next step in the development if the implementation strategy. Several factors pertaining to conventional, functional financial management which impede on effective project management must be addressed. Firstly a lack of, or insufficient incentives to perform on any, or all of the project management success factors. Secondly, zero-based annual budgeting instead of continuous project budgeting. Thirdly a lack of project-based activity and output orientated cost management system, and finally financial management systems and software that are not compatible with project management systems and software.

8. Project leaders quite often feel threatened, because they are mostly taken out of their functional areas where their specialist functional/technical knowledge were their power bases, and thrusted into new, predominantly managerial and facilitation roles. The skills, stresses and strains of the latter are completely different from that of their occupation hitherto. Furthermore in a multi-functional project the value of their "power bases" is relinquished, and at first without the security of a new career as such. Therefore, the efforts required to master the management of projects are met with little real enthusiasm. Cognisance of this potentially disrupting effect and continuous support and comforting of the project leaders, must be a primary duty of the PSG

9. Project management operates in principle crossfunctionally. From the outset conflict over project priority, resource allocation, differing monitoring roles of functional managers and project leaders and the decision making authorities of project leaders are omnipresent. Instituting an official conflict resolution procedure under the auspices of the PSG should receive high priority on the project management implementing strategy.

10. The success of a multi-disciplinary / -functional project, as well as the successful management thereof is entirely dependent on the integration of the diverse functional inputs into a single point of responsibility. This is organised by way of a matrix organisation, where the project (organisation / team) is overlaid horizontally over the natural vertical inclinations of the incumbents of the said functions. Clearly this transfunctional orientation of the project causes major organisational upsets, to the point where an organisational culture realignment, supportive of the trans-functional or project approach becomes mandated. The development of such a project management supportive organisational culture thus becomes a major element of the implementation strategy.

11. No evidence could be found in any literature of any empirical proof, with which to convince the decision makers that project management is in fact the better way to ad-hoc goal achievement. As part of the implementation strategy, carefully selected pilot projects (up to five) should therefore be run to demonstrate the usefulness of the project management process for ad-hoc goal achievement.

These pilot projects are also utilised as a "laboratory" to customise generic principles and techniques to the organisation's local circumstances, as well as to develop its own set of rules. The role of the mentor is deemed extremely important to assure conformance to accepted generic protocols and best practices and procedures.

12. One of the outcomes of a project plan is the project schedule. This contains the activities required to achieve the deliverable of the project, the logical sequence of the activities, shows the interdependencies between the activities, the estimated duration of each activity and thus establish the duration or timeline for this project as a whole. The schedule constitutes the workflow of the project and is the final element of the implementation strategy.

\section{Second dimension: Develop a project management supporting organisation culture}

Van der Post (1996:148) summarises the views of many authors in his extensive research, when he states that culture implies the existence of certain dimensions or characteristics that are closely associated and interdependent and that guide the actions of a group of people, i.e. that group's (or organisation's) "way of doing things". The question that involuntarily comes to mind in the quest for effective project management, is whether the project management "way of doing things" is indeed so significantly different from the conventional (functional) "way of doing things" in an organisation, as was alluded to in the introduction? For organizations that execute projects as well as conventional operations, the former is inevitably organized by way of overlaying a trans-functional, project specific organisation (the project team) ad-hoc over the (vertical) functions specific structure (Kerzner, 1992:120; Kezsbom \& Edward, 2001:47-52). Most text books quote any number of the following as intrusions into the de facto functional organizational culture, associated with operating the two approaches concurrently in the same organisation:

- $\quad$ the team members are answerable to two bosses - the project leader and the functional manager;

- $\quad$ heads of functional departments are obliged to train and make resources available to projects and therefore perceive the authority of team leaders as an invasion into and a threat to their own domain;

- the meritorious evaluation of team members could reside with persons other than their traditional bosses;

- $\quad$ the leadership for and implementation of a project can take place outside of the "normal” functional structure;

- $\quad$ hierarchy awareness is diminished because persons of any hierarchical level may give an input to the team and be subordinate to the authority of the team leader; 
- departmental heads become removed from the high load of purpose and action, associated with projects;

- $\quad$ pursuing projects are perceived to be more dynamic than pursuing functional objectives, which cause conflicts regarding priorities and resources; and

- $\quad$ project teams are often tightly knitted units with own codes of conduct that lead to confrontations in the "mother" organization.

Evidently the trans-functional approach can potentially cause major organizational disruptions that should be met by organizational culture realignment to the new requirements.

\section{The dimensions of a project management} supporting organizational culture

That an organizational culture can be identified and developed to pursue a specific goal, by way of identifying and then inculcating the appropriate constituent dimensions, is widely recognized, notably Ford and Randolph (1992), Goffee and Jones (1996), Van der Post (1996), Graham and Englund (1997), Kezsbom and Edward (2001). In pursuit of this principle, the author identified a project management supporting organizational culture containing nine dimensions (Brown, 2000:14 - 17; Brown, 2007:30 (Table 4)), by applying the approach of Goffee and Jones (1996), who describe different organizational cultures in terms of the applicable combinations of sociability (team spirit) and solidarity (goal drivenness), to the 15 dimensions of organizational culture established by Van der Post (1996).

Morrison (2005:127 (Table 6.3)) developed a construct with 12 dimensions of a project management supporting organizational culture. This research involved a literature study of 254 sources, followed by an empirical survey involving respondents from three levels of management of thirty organizations heavily engaged in the management of projects.

The author then collated Morrison's results with those mentioned above and adapted these results to propose 14 dimensions of a project management supporting organizational culture. Table 1 describes this construct in the form of an organizational cultural diagnostic. The author bases the validity of a project management supporting organizational culture on the fact that the four very different studies executed with disparate methods all produced basically congruent results.

\section{Third dimension: Establish an appropriate management role for the project leader with reference to the type, size and complexity of a project}

The projects of a sizeable organisation possess several characteristics that can lead to their classification on a continuum from simple to complex. A singular management approach to all of an organisation's projects will invariably lead to frustration and resistance from project staff on smaller projects who see it as too much extra work, not "justified" and too time consuming for a small project. It will also invariably lead to frustration of staff on big projects due to them not getting the extra support that their big projects require and which that one methodology cannot provide. The particular methodology applied to a specific project must therefore fit a project's characteristics, and not the other way round (Ford \& Randolph, 1992:271, 272, 282; Frigenti \& Comninos, 2002:45). This means that the management role for the project leader must be appropriately aligned with the type, size and complexity of a project.

The two basic tenets determining such alignment are, firstly the relationship between the coordinational requirements for and the functional inputs into the project, both of which change over the continuum. Secondly the level of authority required to enable "commandeering" the resources for the project that also changes over the continuum. The changing influence of project complexity on these two tenets is shown in Figure 1.

Figure 1 shows for small non-complex projects, the relative functional influence to be dominant as only one or two functions are involved with virtually no coordination (project management input) required and the decision making authority associated with a project coordinator will suffice. Concomitant with increase in the size of a project, it can be expected that gradually more functions input concurrently and the relative influence of each function decreases. Therefore the coordination required between the functional inputs increases, resulting in increased importance of the project coordinator's role, with an associated higher level of decision making authority. On the continuum from simple to complex a point is reached where the authority associated with a project coordinator is not enough to "enforce" adherence to the (planned) schedules and resource supply, by the functions. Clearly this can be detrimental to the project as increased diversity of inputs can be expected to lead to more intense interdependence, cooperation, coordination and synchronisation required of functional inputs. To enable the project leader to exert sufficient influence beyond that point on the continuum, his / her role needs to be changed to that of an autonomous manager with the concomitant decision making authorities.

The decision to change the role of the project leader from that of being only a "coordinator" to that of being a "manager" must clearly rest with top management as it can have numerous ramifications for the organisation (not the subject of this paper). Top management must firstly institute a classification system for its projects over the continuum and sort all projects into a relevant "class". For the 61 organisations represented in the study group of Brown (2000), the group of determinants which were found to describe the range of the scope of their projects is shown in Figure 2. Clearly this list is not exhaustive, for example one may expect that the technology applied in a project, which can range from "simple" or "known" to "complex" or "unknown”, to have been included in Figure 2. 
Table 1: Cultural diagnostic, containing 14 dimensions of organizational culture supportive of project management

\begin{tabular}{|c|c|c|c|}
\hline Dimension & Description & $\begin{array}{c}\text { Approaches supportive of } \\
\text { project management }\end{array}$ & $\begin{array}{c}\text { Approaches not supportive } \\
\text { of project management }\end{array}$ \\
\hline Strategic direction & $\begin{array}{l}\text { Clear direction at top level that } \\
\text { aligns all projects with } \\
\text { organization's strategy }\end{array}$ & $\begin{array}{l}\text { Clear mission and strategy. } \\
\text { Project justification and } \\
\text { prioritization procedures aligned } \\
\text { with strategy }\end{array}$ & $\begin{array}{l}\text { Little focus, opportunistic } \\
\text { goals not measured w r.t. } \\
\text { mission. Little systematic } \\
\text { project portfolio build-up }\end{array}$ \\
\hline External focus & $\begin{array}{l}\text { Focus on market and external } \\
\text { opportunities }\end{array}$ & $\begin{array}{l}\text { Concerned with customer } \\
\text { satisfaction and to maintain } \\
\text { competitive edge. Always } \\
\text { pursue renewal initiatives }\end{array}$ & $\begin{array}{l}\text { Tend to be complacent about } \\
\text { own products and position in } \\
\text { the market }\end{array}$ \\
\hline Culture management & $\begin{array}{l}\text { Shaping the organization's } \\
\text { culture towards project } \\
\text { management }\end{array}$ & $\begin{array}{l}\text { Cross-functioning fostered } \\
\text { through mutual interests and } \\
\text { goals, sharing information and } \\
\text { interrelation awareness }\end{array}$ & $\begin{array}{l}\text { Low strategic intervention to } \\
\text { reform bureaucratic processes } \\
\text { and functional solidarity }\end{array}$ \\
\hline Organizational cohesion & $\begin{array}{l}\text { Organizational } r \text { subunits } \\
\text { encouraged to support project } \\
\text { teams }\end{array}$ & $\begin{array}{l}\text { Low hierarchy \& formality } \\
\text { awareness, socializing to } \\
\text { enhance team formation, team } \\
\text { based awards }\end{array}$ & $\begin{array}{l}\text { Low application of team } \\
\text { formation techniques, } \\
\text { individual recognition i.s.o. } \\
\text { team recognition }\end{array}$ \\
\hline Performance orientation & $\begin{array}{l}\text { Energy directed and controlled } \\
\text { towards high performance }\end{array}$ & $\begin{array}{l}\text { Pro-active, focused, action } \\
\text { orientated communication. } \\
\text { Stimulate will to complete } \\
\text { projects within targets }\end{array}$ & $\begin{array}{l}\text { Re-active focus on avoidance } \\
\text { of past failures. Scant } \\
\text { incentives to raise } \\
\text { performance above minimum } \\
\text { requirements }\end{array}$ \\
\hline Conflict resolution & $\begin{array}{l}\text { Procedures to resolve conflicts } \\
\text { about resource allocation and } \\
\text { project priorities in place }\end{array}$ & $\begin{array}{l}\text { Project leaders encouraged to air } \\
\text { conflicts. Guaranteed freedom } \\
\text { to express differences }\end{array}$ & $\begin{array}{l}\text { Project leaders reluctant to air } \\
\text { conflicts. Cautious to act and } \\
\text { scared of reprimand }\end{array}$ \\
\hline 7. $\begin{array}{l}\text { Disposition towards } \\
\text { change }\end{array}$ & $\begin{array}{l}\text { Management willingness to } \\
\text { replace old practices with new } \\
\text { ones }\end{array}$ & $\begin{array}{l}\text { Employees encouraged to be } \\
\text { creative and innovative. } \\
\text { Intensive and active interaction } \\
\text { and reflection }\end{array}$ & $\begin{array}{l}\text { Dogmatic orientation about } \\
\text { practices that worked well in } \\
\text { the past. }\end{array}$ \\
\hline Employee participation & $\begin{array}{l}\text { Team members perceive } \\
\text { themselves to be allowed to } \\
\text { participate in decision making } \\
\text { processes }\end{array}$ & $\begin{array}{l}\text { Members readily contribute to } \\
\text { information for decision making } \\
\text { and consensus seeking }\end{array}$ & $\begin{array}{l}\text { Members leave decision } \\
\text { making to higher levels, } \\
\text { reluctant to question and don’t } \\
\text { seek consensus }\end{array}$ \\
\hline 9. Locus of authority & $\begin{array}{l}\text { Degree of authority, freedom } \\
\text { and independence bestowed on } \\
\text { project leaders }\end{array}$ & $\begin{array}{l}\text { Project leader's authority } \\
\text { concomitant with responsibility } \\
\text { and accountability for project }\end{array}$ & $\begin{array}{llr}\text { Project leader } & \text { has } \\
\text { accountability } & \text { for project but } \\
\text { insufficient authority } & \text { to } \\
\text { commandeer resources } & \\
\end{array}$ \\
\hline 10. Management style & $\begin{array}{l}\text { Management provides clear } \\
\text { communication, assistance and } \\
\text { support to project teams }\end{array}$ & $\begin{array}{l}\text { Visible support to project from } \\
\text { top management in accordance } \\
\text { with project priorities }\end{array}$ & $\begin{array}{l}\text { Confusion about project } \\
\text { priorities without clear project } \\
\text { portfolio procedures } \\
\end{array}$ \\
\hline $\begin{array}{l}\text { 11. Process and systems } \\
\text { support }\end{array}$ & $\begin{array}{l}\text { Organization pursues supporting } \\
\text { and enabling systems and } \\
\text { procedures }\end{array}$ & $\begin{array}{l}\text { Systems and software } \\
\text { compatible with that of the } \\
\text { organization; sound knowledge } \\
\text { management }\end{array}$ & $\begin{array}{l}\text { System compatibility lacking } \\
\text { with knowledge gained from } \\
\text { experience not captured / } \\
\text { formalised }\end{array}$ \\
\hline $\begin{array}{l}\text { 12. People management } \\
\text { orientation }\end{array}$ & $\begin{array}{l}\text { Organization maintains a } \\
\text { flexible and innovative character }\end{array}$ & $\begin{array}{l}\begin{array}{l}\text { Focus on innovative, risk taking, } \\
\text { entrepreneurial } \\
\text { patterns }\end{array} \\
\end{array}$ & $\begin{array}{l}\text { Focus on status quo, maintains } \\
\text { rules and supervision, risk } \\
\text { avoidance }\end{array}$ \\
\hline 13. Decision making rationale & $\begin{array}{l}\text { Decisions making driven by the } \\
\text { interests of the organization } \\
\text { based on systematic analysis of } \\
\text { facts }\end{array}$ & $\begin{array}{l}\text { Systematic decision making } \\
\text { based on facts and data prevails; } \\
\text { always only in the interest of the } \\
\text { organization }\end{array}$ & $\begin{array}{l}\text { Quick gut-feel decision } \\
\text { making; often in the interest of } \\
\text { individuals / political concerns }\end{array}$ \\
\hline 14. Communication flow & $\begin{array}{l}\text { People openly communicates up } \\
\text { and down and across lines }\end{array}$ & $\begin{array}{l}\text { Free distribution of information. } \\
\text { High levels of trust and } \\
\text { knowledge sharing }\end{array}$ & $\begin{array}{l}\text { Information flow erratic, used } \\
\text { for personal advantage. Bad } \\
\text { news smothered }\end{array}$ \\
\hline
\end{tabular}



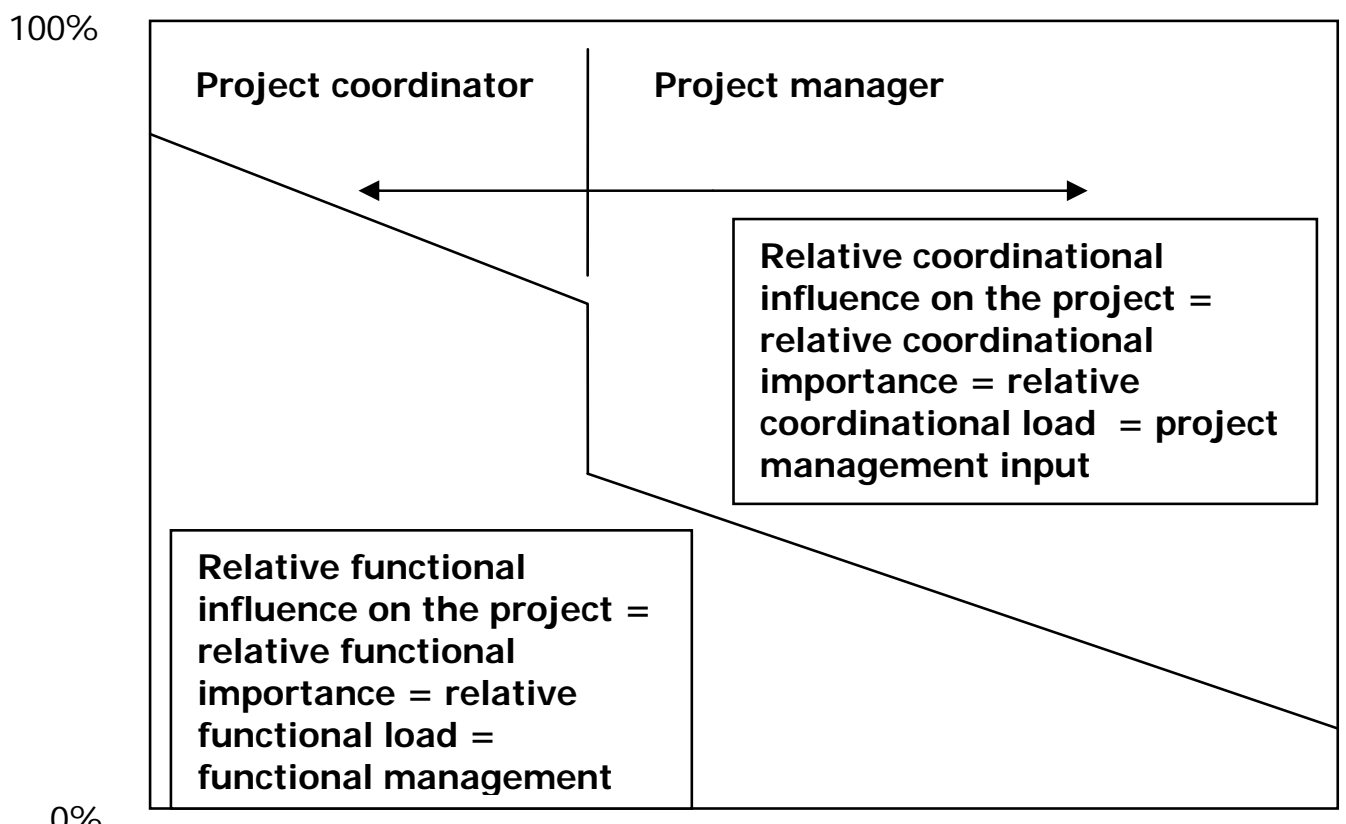

Small, simple

project
$0 \%$

Big, complex

project

Figure 1: The changing relationship of the functional load to the project management load along the continuum of project complexity (size).

Source: Adapted from Kerzner, 1992:142 (Figure 3-16).

\begin{tabular}{|lll|}
\hline Small (money) & $\rightarrow$ & Big \\
Short (time) & $\rightarrow$ & Long \\
Limited human resource needs & $\rightarrow$ & Extensive human resource needs \\
Simple & $\rightarrow$ & Complex \\
Low importance & $\rightarrow$ & High importance \\
Single discipline & $\rightarrow$ & Inter-disciplinary \\
Goal is function-bound & $\rightarrow$ & Goal is not bound to a specific function \\
Low process involvement & $\rightarrow$ & High process involvement \\
Low co-ordination need & $\rightarrow$ & Managerial intion need predominant \\
Functional input predominant & $\rightarrow$ & Managerially skilled scientist \\
Pure scientist & $\rightarrow \rightarrow$ & Output driven \\
Input driven & & Project management \\
Project support & & Big, complex project \\
\hline Small, simple project & & \\
Increasing scope of project &
\end{tabular}

Figure 2: Continuum of project classification determinants

Source: Brown (2000).

Then must follow the allocation of an appropriate organisational structure, management role and decision making powers to each class. Only then should a suitable project leader (coordinator/manager/super manager(?)) for that class of project be selected and appointed.

Clearly the chosen project management structure must also fit into the organisation's culture, strategy and systems
(Brown, 1997:122-131), as discussed earlier. Boar (1998:24) opines that the balance between responsibility, accountability and delimitation of authority should be major considerations when attaching the appropriate project management structure and the appointment of a suitable project leader to a specific class of project. 


\section{Fourth dimension: establish a balanced relationship between the project leader's responsibility, authority and accountability}

To enable a project leader to assume the responsibilities for the execution of a project, he/she needs to acquire resources and schedule their application against targets of cost and time. For in-house resources this acquisition is done by way of service level agreements negotiated with departmental heads as the suppliers. For outsourced resources contractual agreements must be negotiated with relevant suppliers. For both approaches authority must be vested in the project leader to enable the said negotiations. According to Kezsbom \& Edward (2001:256) and Mantel et al. (2001:3) this represents, traditionally, one of the biggest problems for the project leader; to be loaded with the responsibility for results, but not (sufficiently) loaded with authority to pursue the resources. Burke (2003:297) refers to this as the “responsibility - authority gap”.

The fundamental issue at stake is the necessary balance of the responsibility for results, with authority to acquire resources, with accountability for the outcomes of the authority applied; commonly known as the "golden triangle of management". Compared to that, the "project triangle" is described by inter alia Frigenti \& Comninos (2002:40) as the necessary balance of the deliverable or performance, with the cost, with the time (duration) of a project. In the realm of project execution, these two sets of balances (triangles) are actually the same as illustrated in figure 3. The workload in a work package is done to deliver the deliverable (at required quality), which is clearly equivalent to the responsibility of the project leader. That can only be executed with the resources acquired (resource hours available), for which the project leader must pay, i.e. the cost, which can only be incurred if the project leader has the authority thereto. Therefore authority can be viewed as equivalent to cost. The time (duration) is calculated from dividing the workload (hours required) by the hours available. However the project leader is accountable to deliver the project on time, whereby time can be viewed as equivalent to accountability.

\section{DELIVERABLE $=$ RESPONSIBILITY}

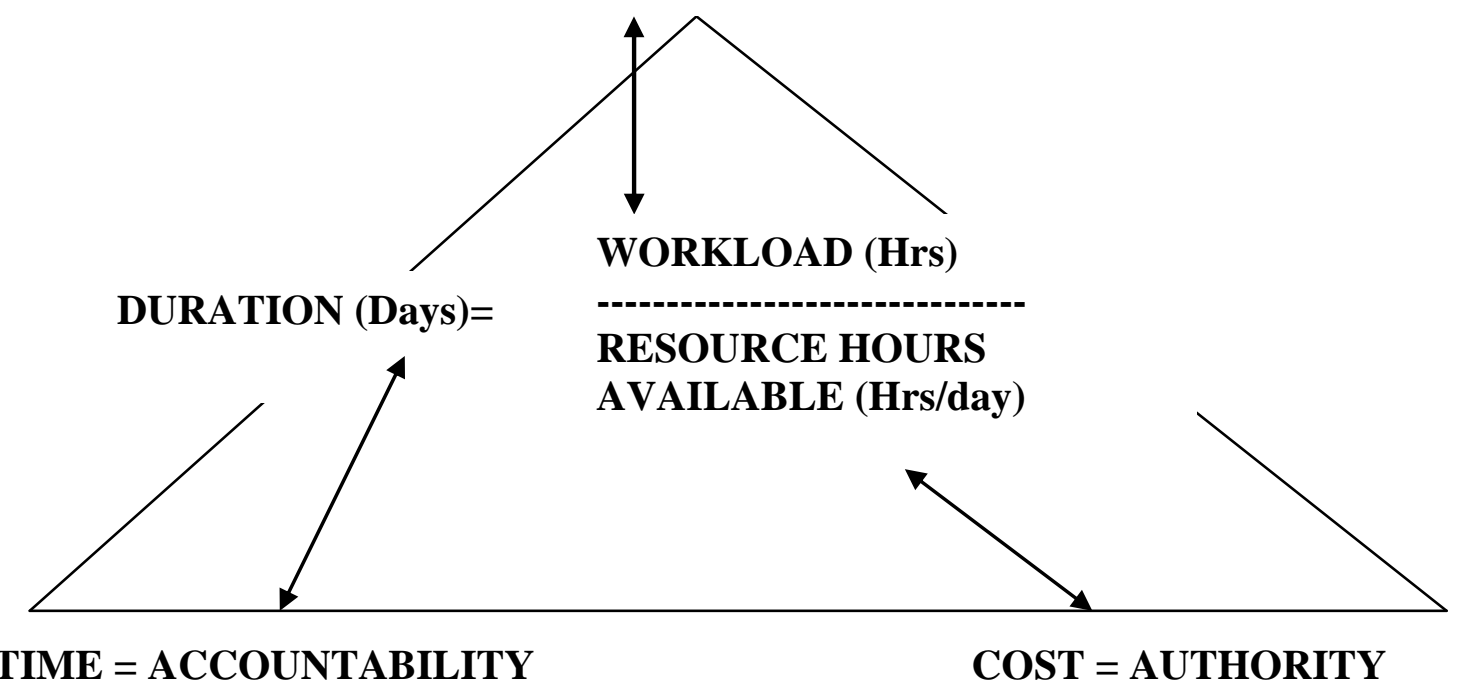

Figure 3: The golden triangle of management superimposed on the project triangle

Source: Author's own representation

The practical implication of these two sets of balances is that a project leader can only be held accountable to deliver the project on time, if he / she is afforded the (sufficient) authority to acquire the resources. Or stated in another way: The project leader can only "guarantee" the client the delivery of the project on time if the client "guarantees" the project leader the resources. The study referred to earlier, shows that about $70 \%$ of project leaders claim that this simple truth, easily proved with the equation for the calculation of project duration superimposed on the project triangle as shown in Figure 3, is not observed by top management.
Fifth dimension: Special efforts must be directed at the development of cross-functional teams and team work

Parker, McAdams and Zielinski (2000:17) define a team as “a small group of people allied by a common goal and sharing performance objectives. They generally have complementary skills or knowledge and an interdependence that requires that they work together to accomplish a common team goal. Team members hold themselves mutually accountable for their results. Such teams are not usually found on the custom organisation charts”. From this definition can be inferred that a project is executed by a temporary, cross-functional team which is participative in 
nature; hence for success the members must be allowed free and equal access to communication. (Ford \& Randolph, 1992:284). This implies mature workers with the ability of working and making decisions quite independently. In consort with the mature worker theme, Pant, Allison and Hayes (1996:56) suggest that project team members require qualities like objectivity, flexibility, not avert to risks, be independent decision makers, low sensitivity for conformity and low power and rule orientation. They should also have the ability to interact smoothly and purposefully and to maintain close ties with other organisational members (i.e. the ability to operate outside their accustomed functional bases).

Other characteristics of successful cross-functionally operating organisations include the following (Mantel et al., 2001:47 - 50; Ford \& Randolph, 1992:273-290; Verma, 1995:157-200; Johns, 1998:1-7):

- top or divisional management understands, is committed to, visibly supports and encourages crossfunctional teams;

- $\quad$ top management operates a system that ensures that all projects are aligned with and are beneficial to the organisational strategy, which serves as a high powered motivation for team members;

- $\quad$ project teams are fully empowered and operate within flattened reporting structures;

- they employ multi-skilled, flexible, versatile and mature project team members;

- they apply project management techniques and disciplines formally;

- $\quad$ effective relationships exist between project and line managers; and

- $\quad$ project leaders have the required independence and authority.

In the study by Brown (2000) the following principles were indicated by in excess of $52 \%$ of the sample group as being important for successful cross-functional operation:

- $\quad$ visible support for the cross-functional teams by top management through clearly aligning their authorities and accountabilities with project priority;

- a mechanism to resolve conflict quickly and effectively;

- bi-lateral respect for the coordinational role of the project leader by the functional managers, and for the specialised functional skill of the functionaries by the project leader;

- $\quad$ effective communication channels and free access to information between project participants;
- willingness of both functional managers and project leaders to negotiate resources and to reconcile project objectives with functional objectives;

- $\quad$ an organisation culture of collaboration, i.e. attitudes of co-operation and helpful behaviour;

- $\quad$ line managers to understand the goal and priorities of the projects in which their staff are involved;

- $\quad$ clear authority for a team member to represent his / her functional area's input;

- $\quad$ line managers to regularly monitor the problems that their team members are encountering;

- include the project leader in the appraisal of team members.

Performance management in project management context means appraisal of a team as well as individual performance (Ford \& Randolph, 1992:273 - 279). In most organisations this implies a radical change to the de facto appraisal approach. Project leaders need to be appraised specifically on how well they interacted with the team. The emphasis for the team members shift to how well did they fit in with and contributed to the team's effort? In the study the respondents were unanimous that matrixed actions cannot be successful unless the emphasis of recognition programs shifts from individual to team rewards.

On the other hand, $78 \%$ of the respondents were convinced that the appraisal of line managers should include the rigor of their support to project teams.

\section{Sixth dimension: Appropriate systems for the facilitation of the project management processes must be provided}

Appropriate systems and software underpinning the project management processes and techniques must be provided (Brown \& Botha, 2005:3). The proper planning, management and monitoring of a project requires constant gleaning of information and communication between the project and the various functional resource and service suppliers. Inter alia activity-based-costing and the earnedvalue approach, are completely dependent on information generated within the domain of financial management. For example the "actual cost of work produced" (ACWP) is compiled from actual payments for materials bought and labour and rented equipment paid from timesheets by the financial controller. Therefore the systems and software for the project management domain must be carefully selected for compatibility with the organisation's existing operational and administrative systems, and particularly with that of the financial management. Otherwise manual transfer, comparison and collating of information between a project and the operational setup must be done, which is clearly too ghastly to contemplate.

In line with a previous argument such systems, software and procedures will also have to support the differing 
administrative and operational needs of the array of projects along the continuum of project size and complexity.

\section{Seventh dimension: Project leaders must be skilled in the project management processes and techniques}

The primary tasks of a project leader in a project is to have the right thing at the right place at the right time, to integrate all the inputs into a single point of responsibility and to lead (or push) the project to timeous completion. All of that requires the application of skills and techniques as specific steps in a systematic and systemic process. However, Botha (2003) found that very few project leaders start their careers in project management, but almost always in one or other functional skill. The basic approach of this paper is that there is a substantial difference between functional and project related actions and behaviours. As concluded by Brown \& Botha (2005:6), proper skilling in project management principles and techniques is in the final instance imperative for effective project management in an organisation.

\section{Conclusion: An organisational framework}

All the departments (functions) of an organisation working diligently, doing their utmost and deliver individually their best towards a project, do not guarantee that the deliverable of a project will be a success. The reason for this is that they collectively do not necessarily form a system (Kezsbom \& Edward, 2001:11\&262). According to Kerzner (1992:69) the success of a system is determined by the interaction of the parts whereby integration can be achieved. With multi-functional projects, that can only be achieved through managing cross-functionally, which implies the addition of an additional element to the process. This horizontal approach will not take place naturally because the incumbents of the functions have naturally a vertical inclination. It must be therefore be deliberately "engineered" and inculcated.

However, the use of appropriate project management processes and tools also do not guarantee that project management will be effective on a continuous basis. This paper integrates several studies which identified several organisational dimensions that can significantly influence project management success. These dimensions run like a golden thread through organisational strategy, structure, culture, systems, behavioural patterns and processes, thereby determining the required internal environment within which project management will flourish.

The first step in this organisational process proposes that project management be formally instituted in an organisation through a thoroughly planned strategy. It is a strategic process equal to any other in an organisation's affairs and cannot be left to chance. The second step is to develop and inculcate a project management supporting organisational culture, i.e. way of doing business. The third step is to classify a project in terms of type, scope and complexity, in order to match the appropriate management and organisational, leadership and decision making systems to the requirements of the project, to avoid the project to be either over- or under-managed. This must also include a proper balance between the project leader's responsibility, authority and accountability for the project. Thereafter the elements of sound matrix management must be inculcated, which means a considerable mind shift away from conventional functional thinking. Then the development of effective cross-functional teams and team work must be attended to. The sixth step is to provide appropriate systems for the facilitation of the project management processes.

In the final instance, and what cannot be overemphasised is that this process will not follow as a natural course of action, simply because a decision towards the implementation of project management was taken. A champion skilled in project management with the responsibility, balanced by authority and accountability for driving the process needs to be appointed, or else it will fall into disarray.

\section{References}

Boar, B.H. 1998. 'Redesigning the IT organisation for the information age', Information Systems Management Journal, 15(3):20-27.

Botha, M.C. 2003. 'Formulating and implementing a strategy for project management in the Eden District Municipality'. Unpublished dissertation for the MBA degree, University Stellenbosch Business School, Bellville.

Brown, C.J. 1997. 'Towards a strategy for project management implementation'. Paper presented to the National Conference of the Australian Institute of Project Management, Gold Coast, Queensland, Australia, 9 - 12 November.

Brown, C.J. 2000. 'The dimensions of a project management supporting organisational culture'. Paper presented to the World Project Management Week Conference, Cairns, Queensland, Australia, 9 - 14 October.

Brown, C.J. \& Botha, M.C. 2005. 'Lessons learnt on implementing project management in a functionally-only structured South African municipality', South African Journal of Business Management, 36(4):1-7.

Brown, C.J. 2007. 'Sustaining the competitive edge of project management', Advanced Management Journal, 72(1):22-32.

Burack, E.H. 1991. 'Changing the company culture - the role of human resource development', Long Range Planning, 24(1):88 - 95.

Burke, R. 2003. Project management planning and control techniques. 4th Edition. Cape Town: Technical Books (Pty) Ltd.

Cleland, D.I. 1990. Project management, strategic design \& implementation. Pennsylvania: TAB Professional \& Reference Books

Clements, J.P. \& Gido, J. 2006. Effective project management. Thompson South-Western, USA. 
Ford, R.C. \& Randolph, W.A. 1992. 'Cross-functional structures: A review and integration of matrix organisation and project management', Journal of Management, 18(2): $267-294$.

Frigenti, E \& Comninos, D. 2002. The practice of project management. London: Kogan Page.

Goffee, R. \& Jones, G. 1996. 'What holds the modern company together?', Harvard Business Review, Nov.Dec:133 - 148.

Graham, R.J. \& Englund, R.L. 1997. Creating an environment for successful projects. San Francisco: JosseyBass Inc.

Gray, C.F. \& Larson, E.W. 2008. Project management - the managerial process. $4^{\text {th }}$ Edition. New York: McGraw-Hill Irwin.

Johns, T.G. 1998. 'On creating organizational support for the project management method', International Journal of Project Management, October: $1-15$.

Kerzner. H. 1992. Project management, a systems approach to planning, scheduling and controlling. $4^{\text {th }}$ Edition. New York: Van Nostrand Reinhold.

Kezsbom, D.S. \& Edward, K.A. 2001. The new dynamic project management, $2^{\text {nd }}$ Edition. New York: John Wiley \& Sons, Inc.

Knutson, J. 1994. 'The top management steering committee'. Paper presented to the PMI $24^{\text {th }}$ annual seminar, Vancouver, Canada, 17-19 October.

Mantel, S.J., Meredith, J.R., Scott, M.S. \& Sutton, M.M. 2001. Project management in practice. New York: John Wiley and Sons, Inc.

Morrison, J.M. 2005. 'Conceptual and empirical investigation into a project management supportive organisation culture'. Unpublished $\mathrm{PhD}$ dissertation, University Stellenbosch Business School, Bellville.

Nicholas, J.M. 1990. Managing business and engineering projects: Concepts and implementation. Englewood Cliffs, New York: Prentice Hall.

Pant, D.P., Allison, C.W. \& Hayes, J. 1996. 'Transferring the Western model of project organisation to a bureaucratic culture: the case of Nepal', International Journal of Project Management, 14(1):53 - 57.

Parker, G., McAdams, J., \& Zielinski, D. 2000. Rewarding teams. San Francisco: Jossey-Bass Publishers.

Tettemer, J.M. 1991. 'Keeping your bosses happy while implementing project management - a management view'. Guide to the PMBOK, PMI. Drexel Hill, Pennsylvania.

Van der Post, W.Z. 1996. 'The relationship between organisational culture and financial performance amongst industrial organisations listed on the JSE for the period 1984 to 1993'. Unpublished Ph.D. dissertation, Graduate School of Business, University of Stellenbosch, South Africa.

Verma, V.K. 1995. 'Organising projects for success. The human aspects of project management'. Guide to the PMBOK, PMI. Drexel Hill, Pennsylvania. 